\title{
PHENOMENOLOGICAL REPRODUCTION in Thompson and Mailer's New Journalism
}

\section{BRENDAN CHAMBERS}

"The truth is no more nor no less than what one feels at each instant in the perpetual climax of the present." - Norman Mailer, "The White Negro"

Tn his classic essay, "The New Journalism and the Image-World: Two Modes of Organizing Experience," David Eason sought to distance interpretations of New Journalism from what he saw as the facile, superficial description of its resemblance to novelistic writing, and to create a more complex conception of the relationship between style, culture, and consciousness. He argued that the widespread view of New Journalism as literary journalism (particularly as propounded by Tom Wolfe) "abstracts the reports from their cultural contexts [... giving] only passing attention to the experiential contradictions represented in many of the reports." ${ }^{1}$ Within his own formulation, Eason proposed instead that we think of two countervailing subdivisions within this body of work, each reflecting a different approach to conceptualizing the relationship of reporter to the cultural fragmentation of the 1960's and 1970's. In so doing, Eason established categories that influence critical discussion to this day. ${ }^{2}$ Eason called the first of these approaches "ethnographic realism." ${ }^{3}$ This mode aims to enter a group and "constitute the subculture as an object of display," from whence "the reporter and reader, whose values are assumed and not explored, are conjoined

1 Eason, David L. "The New Journalism and the Image-World: Two Modes of Organizing Experience" in Critical Studies in Mass Communication (1984), 52.

2 For instance, Robert Alexander's analysis of Thompson's Fear and Loathing in Las Vegas' role in the history of narrative journalism, or Norman K. Denzin's work describing performance ethnography.

3 Eason, "The New Journalism and the Image-World: Two Modes of Organizing Experience," 51. 
in the act of observing," work "to reinvent textually the consensus which cultural fragmentation had called into question." "This approach, exemplified by the work of Tom Wolfe, effectively places the reporter and his reader outside of a given event (or cultural moment, as Eason was more wont to describe it), and in the passive role of bystander, observing without participating. By unifying them in this role, the text positions both reader and reporter within a shared culture and value system, often appropriating obsolete codes of understanding to do so. Scenes and subcultures are made accessible to the reader only by depicting him in relation to the (assumed) shared dominant cultural framework. Positioned in that way, the journalist then penetrates the world of the Other, affording the reader with a passage into its hidden reality. In Eason's view, ethnographic realism, at its core, largely sought to assuage the fears of mainstream audiences about the fracturing of society by comparing what appeared to be new and frightening cultural changes to supposedly similar movements of the past: in Wolfe's case, for instance, linking the worryingly impenetrable symbolic world of Ken Kesey's 'Merry Pranksters' to the base human religious impulse. To Eason, this explanatory role also disguised an unequal power dynamic between reporter and reader. Though they are unified in the assumed shared cultural understanding, writer and reader are often simultaneously placed on uneven ground, with the reporter in a paternal role, guiding the reader from ignorance to understanding. ${ }^{5}$

Eason terms his second variant of New Journalism-the one that will interest me in the following pages_ " cultural phenomenology." This approach takes in some ways an entirely opposite angle in addressing cultural fragmentation. It not only acknowledges, but also embraces the mindset that "there is no consensus about a frame of reference to explain 'what it all means."'6 It equivocates on calling any one experience "reality," instead sitting with the "experiential contradictions represented in many of the reports." Finally, it joins together reporter and reader in the co-creation of a reality, engaging in a "multi-level interrogation, including that between writer

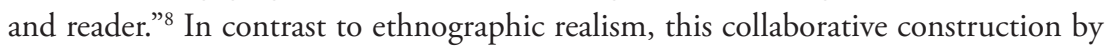
reader and author puts both on a more equal footing, reflecting the cultural values of the time period that produced it. While ethnographic realism can exist at any time, cultural phenomenology is representative of a specific cultural moment; it is a manifestation and product of the 1960's and early 1970's, a time when "the doctrine of representation had crumpled [and] the center which separated image and reality were not holding." " Each approach reflects a methodology of understanding, a means to the end of reckoning with an unrecognizable world. 
As Eason suggests, the divergent means of "coming to terms with disorder" in the rapidly changing media world are reflected in the meta-analyses that crop up in each style. ${ }^{10}$ As Mas'ud Zavarzadeh explains in his Mythopoeic Reality, given the expansion and diversification of mainstream news media in the 1960s, readers grew to be wary of any text that sought to totalize experience, which presented a singular, universal understanding of events, as both traditional literature and reportage had. In Zavarzadeh's telling, they began to eschew anything that presented a single, solid "harmonizing principle behind manifold reality." ${ }^{11}$ Instead, readers often sought what New Journalism offers: a self-conscious, self-aware approach to representation, which recognizes the limitations of individual experience and makes explicit reference to them, so as to most accurately present information to the reader. More traditional forms of ethnographic realism attempted to keep pace with these changes, though it often left little room for the reader to decide whether the journalist's representation was accurate, taking that truth-claim as a given. Ethnographic realism often creates the illusion that the processes of its creation could produce nothing other than an objective representation of reality, despite the sculpting necessarily done by matters of selection, point of view, and so on. I see Eason's conception of cultural phenomenology as the opposing approach, calling attention to the inherent limitations of its form and method. It is not only cognizant of these limitations, but it also makes use of them in order to investigate, in conjunction with the reader, the possibilities available to construct a world "rooted in the interaction of 'images of reality' and 'the reality of images."' 12

If asked to distill the distinction between the two styles to a single phrase, I nominate authorial self-reflexivity. Cultural phenomenology recognizes the existence and effects of this liminal image-world ${ }^{13}$ on writing itself and any attempts, therefore, to represent such a world. By taking stock of the contemporary cultural moment, and the effects of the proliferation and dissemination of media, writers using a culturalphenomenological approach are careful to track the effects that the image-world have on their own actions and the events that they attempt to report. This reciprocity within Eason's second model — which is quite similar, as he acknowledges, to what Zavarzadeh terms a "testimonial" approach to nonfiction novel writing-even shapes the decisions of the journalist as he is writing. ${ }^{14}$ If, for example, Norman Mailer changes his behavior to conform to, or to challenge, the constructed media image of Norman Mailer, then that image influences his account of "the real." In this way, the author serves as a vehicle to represent our new lives simultaneously in the world, and

10 Ibid., 54.

11 Zavarzadeh, Mas'ud. The Mythopoeic Reality: The Postwar American Nonfiction Novel. (University of Illinois Press, 1976)

12 Eason “"The New Journalism and the Image-World: Two Modes of Organizing Experience," 55.

13 For the purposes of this paper, the image-world is "a realm which blurs the distinctions between fantasy and reality," one which challenges the traditional dichotomy of image and real, instead imagining "a world in which image and reality are ecologically intertwined" (Eason 54, 53). In practice, this is the conception of reality, formed through the consumption of media and experience, which exists in the collective consciousness of society.

14 Zavarzadeh, The Mythopoeic Reality: The Postwar American Nonfiction Novel, 128. 
outside of it, in the image-world. The distinction between the two-to this historical point well-established-has, in response to reality's conceptual fragmentation, become blurred. Understandings of reality influence understandings of the self; thus, the self must now be understood to be similarly fractured, or lost in the liminal space that our "technotronic society" has opened between the image and the real. ${ }^{15}$

I will now examine how Eason's phenomenological method and Zevarzadeh's testimonial approach ${ }^{16}$ are manifested in the works of Hunter S. Thompson and Norman Mailer. I will examine how Thompson's Fear and Loathing in Las Vegas and Mailer's Armies of the Night conform to-and/or complicate-the categories that Eason postulates. I am interested in the reciprocal manipulation of artistic practice and public image in both writers, as well as the relation of that manipulation to each authors' claims regarding epistemological authority. Additionally, I will explore both authors' use of writing as a reconstitution of self, using the lens of Eason's conception of cultural fragmentation as a point of departure. This question is critical to reckoning with the full scope of their works, as the centrality of self is an inherent characteristic of subjective reportage.

Hunter S. Thompson's Fear and Loathing in Las Vegas embodies Eason's description of cultural phenomenology as a "symbolic quest for significance in a fragmenting society." ${ }^{17}$ Las Vegas's image-world increasingly fractures the supposed object of his quest_an "American Dream" now irreparably divided into bike racers at the Mint 400, the police at the National Conference of District Attorneys, or the various outcasts and addicts who populate the city's casinos and fringe-making the search for concrete, universal truth increasingly more suspect and improbable. The actual quest thus becomes Thompson's own struggle — and, at times, a fruitless quest - to establish new avenues for epistemological authority by constantly shifting stylistic modes and journalistic strategies. Thompson's "savage dream" both exposes and displays the inconsistencies inherent in his own storytelling so as to construct more truthfully a new, fragile and even "failed" reality with his reader. ${ }^{18}$

It is impossible to say definitively whether Thompson intended the process for this work as a rhetorical strategy, that is to say, understood the impossibility of finding a universal framework through which to unify his subjects. But what is certain-or, at least, what most critics believe ${ }^{19}$ — is that Thompson embraces this disunity, working to document "what it feels like to live in a world in which there is no consensus about

15 Zavarzadeh, 1.

16 The testimonial nonfiction novel, as Zavarzadeh terms it, "assumes that the only authority on appearance and existence is the witness himself." In other words, that the author's epistemological authority derives from presence at an event, and that the only information that can be conveyed with absolute authority is that which was registered by "one's participating senses" (128).

17 Eason, "The New Journalism and the Image-World: Two Modes of Organizing Experience," 52.

18 In his "Jacket Copy to Fear and Loathing to Las Vegas: A Savage Journey into the Heart of the American Dream," Thompson describes the work as a "failed experiment in Gonzo Journalism."

19 See, for instance, Hollowell, John. Fact \& Fiction: The New Journalism and the Nonfiction Novel. (University of North Carolina Press, 1977), 11. 
a frame of reference to explain 'what it all means."'20;21 Because of this, he makes forays into a variety of avenues for authority, seeking a method of communication that can convey experience. Thus on a diegetic and conceptual level, Fear and Loathing in Las Vegas serves simultaneously as a representation of the new "supramodern" world and as a documentation of Thompson's attempts at recording it. ${ }^{22}$

Thompson's ultimate task, of course, is to establish the disunity of American society in the ' 60 s and ' 70 s and to articulate the absence of a unifying cultural framework (represented in FLLV by the American Dream). After eating at Terry's Taco Stand, near the end of their ostensible quest, Duke and Gonzo reach what is left of the club they think is called the American Dream, finding only "a huge slab of cracked, scorched concrete in a vacant lot full of weeds," and are informed that "the place had 'burned down about three years ago," leaving little interpretation necessary for the reader. ${ }^{23}$ It is not by accident that Thompson chose Las Vegas as the backdrop for this tale of fragmentation. The city is the preeminent example of what Eason calls "the marketing of worlds of experience," and, therefore, is the ideal place to bring into question "the relativity of all worlds, including one's own." ${ }^{24}$ Las Vegas is also a perfect example of the bidirectional influence of the image-world, where "image and reality are ecologically intertwined." ${ }^{25}$ Full of neon lights, unsavory spectacles, and uninhibited hedonism, Las Vegas is the "vortex" of the American Dream, a grotesque paradise and a world of its own. ${ }^{26}$ These excesses of Las Vegas of course influence its image, but to the same degree the collective perception of the city as a haven for vice and excess forces it to cater to this conception, the reality thus changing to conform to the image.

The same transformative process occurs through Thompson's strategy of internalizing the image-world into a distorted caricature of his own identity. Raoul Duke is famously a rum-guzzling, drug-frenzied maniac: the "Gonzo" journalist. Even Thompson's so-called "biographies" document a self that has morphed into that Gonzo identity, as Thompson and his constructed image became inseparable. ${ }^{27}$

20 Fear and Loathing in Las Vegas was originally serialized in two parts in Rolling Stone magazine in 1971 and 1972. As Thompson describes it, he intended to travel to Las Vegas and cover the Mint 400, "to buy a fat notebook and record the whole thing, as it happened, then send in the notebook for publication-without editing." Instead, he laid the foundation for the work during "about 36 straight hours in [his] room at the Mint Hotel...writing feverishly in a notebook about a nasty situation that I thought I might not get away from" which was then compiled over the next six months at the behest of his editor, and put into print later that year.

21 Eason, "The New Journalism and the Image-World: Two Modes of Organizing Experience," 52.

22 Zavarzadeh, The Mythopoeic Reality: The Postwar American Nonfiction Novel, 1.

23 Thompson, Hunter S. Fear and Loathing in Las Vegas: A Savage Journey into the Heart of the American Dream. (Random House, 1998), 168.

24 Eason, "The New Journalism and the Image-World: Two Modes of Organizing Experience," 51.

25 Ibid., 53.

26 Thompson, Fear and Loathing in Las Vegas: A Savage Journey into the Heart of the American Dream, 47

27 The biography written by E. Jean Carroll, for example, opens with a schedule of Thompson's daily drug use, beginning:

3:00 p.m. rise

3:05 Chivas Regal with the morning papers, Dunhills

3:45 cocaine 
This image is constructed to a strategic end, however. By suffusing his writing with alternating mania and introspection, Thompson places himself in the tradition of the blind prophet, a strategy that stretches back to Tiresias, one who ostensibly cannot see, but who, in fact, "sees" better than most. Visionary hallucinations afford the opportunity to place the symbolic in the real without straying too far into the realm of the fictional: a hotel lounge full of humanoid lizards cannibalizing one another stand as a report of Thompson's true lived experience, while simultaneously representing an allegorical understanding of Las Vegas' patrons.

In Thompson's visionary brand of New Journalism, therefore, individual experience remains the highest source of epistemological authority, even as its hallucinatory style testifies to the author's refusal to attempt a supposedly "objective" representation of reality. He eschews presenting a "harmonizing principle behind manifold reality," instead working constantly to remind the reader of the constructedness of the very identity that bears witness to a surreal narrative. ${ }^{28}$ Throughout Fear and Loathing, for example, Thompson inserts small tags that allude to his process of creating the story, but they are themselves documents of immersion, chaos, haste and disorder: they are the notes from which he constructs his account, scribbled on "a pocketful of keno cards and cocktail napkins," or on the handful of ink splotches splattered throughout the text, as if the pages the reader holds were torn straight from Thompson's handwritten journal. ${ }^{29}$ Likewise, he includes qualifiers such as "As I recall" and "Memories of this night are extremely hazy," so as to be candid with readers about his state of perception in a way that both qualifies and authenticates his report. ${ }^{30}$

Perhaps the most revealing moment is the one in which Fear and Loathing claims to offer the rendering of an event from Thompson's own notebook, sans edits; the section entitled "Breakdown on Paradise Boulevard" is presented as simply the transcript of the conversation between Duke and Gonzo. The editor's note, which heads the section, states:

At this point in the chronology, Dr. Duke appears to have broken down completely; the original manuscript is so splintered that we were forced to seek out the original tape recording and transcribe it verbatim. We made no attempt to edit the section, and Dr. Duke refused even to read it [...] In

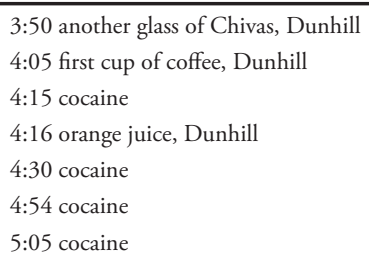

28 Zavarzadeh, The Mythopoeic Reality: the Postwar American Nonfiction Novel, 8.

29 Thompson, Fear and Loathing in Las Vegas: A Savage Journey into the Heart of the American Dream, 41.

30 Thompson, 37, 41. 
the interests of journalistic purity, we are publishing the following section just as it came off the tape. ${ }^{31}$

In this section, we might say, Thompson operates somewhere between Zavarzadeh's testimonial and notational modes, complicating their distinction in his process of searching for avenues to authority. While the testimonial mode, Zavarzedeh writes, derives epistemological authority from presence during an event, the notational mode typically does so through the direct, unedited nature of the work, where the author serves only to record the event verbatim for the reader and to reproduce it exactly. Thompson intended Fear and Loathing to toe the line between the two. He sees "the eye $\&$ mind of the journalist [...] functioning as a camera," and wants the material to be unedited once recorded, but also recognizes that "the writing would be selective \& necessarily interpretive," since it is filtered through the lens of the author's experience. ${ }^{32}$ The above section exemplifies Thompson's operation in this liminal space: it is supposedly a direct recording of the events as they occurred, transcribed from "the original tape recording," but given that it exists in a work that makes editorial decisions in other sections means, by necessity, that its inclusion is an editorial decision. In this way, Thompson operates in both modes simultaneously, notationally including verbatim recordings while testimonially shaping the narrative through decisions that most accurately represent his subjective experience. Though Thompson writes off this moment by judging the work "a victim of its own conceptual schizophrenia," he tempers his own dismissal with a coda, claiming it as "a first, gimped effort in a direction that Tom Wolfe calls 'The New Journalism' has been flirting with for almost a decade." 33

Perhaps most importantly, these moments of narrative discontinuity — from reminders of narrative construction to sudden style changes-execute a sort of Brechtian fourth-wall break, bringing readers out of an essentially immersive narrative and forcing them to evaluate their active participation in a more distanced, critical way. Through this, such readers are inoculated against taking the work as representative of the world, but rather shown that it is a world in a multitude of worlds. In Eason's formulation, Thompson invites the reader to engage in a "multi-layered interrogation of communication [...] between the writer and the reader, as a way of constructing reality." 34 Readers are empowered to reconstitute their own understanding of the reality presented to them-given the ostensibly unqualified facts of the experience and its conveyance-and thereby accept or reject its truth.

Norman Mailer was as, if not more, aware than Thompson of the image-world, and has worked to complicate, engage, and interrogate traditional modes of representation. The first page of Armies of the Night opens with a selection from Time portraying

33 Thompson, Hunter S. The Great Shark Hunt: Strange Tales from a Strange Time. (Picador, 2012), 123, 122.

34 Eason, "The New Journalism and the Image-World: Two Modes of Organizing Experience," 52. 
him as an uncontrolled drunk, "slurping liquor from a coffee mug" and expounding upon the lack of bathroom facilities in the theater where he is speaking. ${ }^{35}$ But just as for Thompson, Mailer's constructed image is part contrivance in the moment (a construct next to the liberal but respectable Robert Lowell) and partly the result of a retrospective literary self-fashioning, as John Hollowell sees it, into "a kind of psychic president, a moral leader" for the contemporary cultural moment. ${ }^{36} \mathrm{He}$ is "semi-distinguished and semi-notorious," "the modern everyday fellow," and "the wild man." ${ }^{37}$ By crafting a complex, dipolar, and at times paradoxical self-caricature, he can implicitly criticize the media processes that would claim singular objective construction of his image while only selectively including observations from the event.

In Armies of the Night, Mailer operates in two distinct modes: Novelist and Historian. As Novelist, Mailer performs two roles. First, the Novelist documents reality as it happened to him; he is, in Mailer's words, the "narrative vehicle for the March on the Pentagon." ${ }^{38}$ However, this experiential record is not entirely forthright or trustworthy. Of course, it includes retrospective revisions, as memory, especially since one apparently so often drunk as Mailer cannot be trusted to be entirely faithful to original perception. This leads to the second role of the Novelist, which is to construct as truthful an image of Mailer as possible, by which the reader can correct the effects of his biases on the narrative. In this way, the image of the Novelist is a tool, an "instrument to view our facts and conceivably study them in that field of light" that his construction of Mailer has produced. ${ }^{39}$ Having established this critical lens, as Historian, Mailer seeks to accurately "elucidate the mysterious character of that quintessentially American event," the March on the Pentagon. ${ }^{40}$ In this way, Armies of the Night serves both as an implicit treatise on behalf of the New Journalism and as an explicit criticism of the old, demonstrating Mailer's belief that reporting "intensity and wholeness of perceptions more closely approaches the truth, or the most important truth, of the thing perceived than objective reporting." 41

By choosing an event whose literal occurrence maps onto his view of the Vietnam War, Mailer creates, as John Hollowell describes it in his Fact and Fiction, an "impressionistic history as seen through the lens of participant-observer." ${ }^{42}$ Mailer presents the two sides of the literal-figurative war through a series of representative images, relying on connotative understandings to bolster his depictions: "healthy Marines, state troopers, professional athletes, movie stars, rednecks, sensuous life-

35 Mailer, Norman. The Armies of the Night: History as a Novel, the Novel as History. (Plume, 2017), 3.

36 Hollowell, Fact \& Fiction: The New Journalism and the Nonfiction Novel, 39.

37 Mailer, The Armies of the Night: History as a Novel, the Novel as History, 13, 15.

38 Ibid., 54.

39 Ibid., 216.

40 Ibid.

41 Begiebing, Robert J. Acts of Regeneration: Allegory and Archetype in the Works of Norman Mailer. (University of Missouri Press, 1980), 135.

42 Hollowell, Fact \& Fiction: The New Journalism and the Nonfiction Novel, 90. 
loving Mafia, cops [etc.] Arrayed against...the Freud-ridden embers of Marxism, good old American anxiety strata — the urban middle class with their proliferated monumental adenoidal resentments. ${ }^{33}$ Rather than maintaining a strict focus on the events that he is reporting on, Mailer often chooses instead to move into exegetical commentary. In this way, like Thompson, he complicates Zavarzadeh's categories of 'nonfiction novel,' using them as shifting modes of representation. Though Mailer seems to operate in the testimonial mode, absorbing and regurgitating events as "witness-participant-narrator," just so often, he shifts to "a private interpretive scheme to reorder the seemingly random incidents into [...] 'a significant form."” This is more in line with Zavarzadeh's exegetical mode ${ }^{44}$, as, for instance, when Mailer moves from a debate with Lowell and Macdonald about the relative merits of being arrested, to an encompassing diatribe on the history of ideological changes of the Left over the course of a paragraph. ${ }^{45}$ In the testimonial mode, he operates as Novelist: a vehicle for experience. In the exegetical mode, he is Historian, providing interpretive commentary tempered by the reader's use of his constructed image.

Diversions characterize Mailer's work; he is even willing to concede the inaccuracy of his perceptions, recording his experience with inconsistencies included. At the height of the March's frenzy, for example, Mailer notes that despite the literal erroneousness of his perception, he experienced a "superimposition of vision," seeing real men fleeing and carrying an N.L.F. flag chased by phantom MP's and policemen. ${ }^{46}$ Though he experienced that vision, he also acknowledges that his perception ran contrary to what other participants reported. In this way, he implicitly acknowledges Eason's premise that phenomenological works are a representation of a world among worlds, each bearing the weight of epistemological authority over itself, but no other. ${ }^{47}$

Perhaps the most distinctive element of Mailer's craft is the voice through which he expresses his ideas. In Armies, he creates the feel of a novel by having an unnamed narrator describe the events that occur to Mailer (of course, the author) as character. In this way, Mailer is able to split his presence and voice, paradoxically laying claim to both omniscience and subjectivity. Mailer the writer is omniscient because of his unfettered access to the thoughts and motivations of Mailer the character. However, he also simultaneously claims epistemological authority through documentation of his subjective experience of the event. Clearly, this technique seems to transcend both Eason's categories as well as Zavarzadeh's. Though Eason asserts that Mailer is operating in the phenomenological mode, third person narration typically creates a voice that mediates experience between recorder and consumer, and thus falls more neatly under the umbrella of ethnographic realism. Mailer wants his narrator to be "an eyewitness who is a participant but not a vested partisan," and indeed often

43 Mailer, The Armies of the Night: History as a Novel, the Novel as History, 34.

44 Zavarzadeh, The Mythopoeic Reality: the Postwar American Nonfiction Novel, 129, 93.

45 Mailer, The Armies of the Night: History as a Novel, the Novel as History, 85.

46 Ibid., 127.

47 Eason, "The New Journalism and the Image-World: Two Modes of Organizing Experience," 51. 
maintains a strong commitment to unfiltered communication of the experience. In other moments, however, he does interpretive work for his readers, presenting them with a rather clean, uncomplicated understanding of events' relationship and meaning. ${ }^{48}$ In this way, Mailer actually sits in a more intermediate space between phenomenology and ethnography, as well as between testimony and exegesis, since he is both the active communicator of participatory experience and passive commenter on the significance of events. Mailer in fact comments on this tension explicitly, explaining that the central figure of his story must, by necessity, be ambiguous, "to recapture the precise feel of the ambiguity of the event and its monumental disproportions." 49

A telling example of Mailer's complication of traditional media's objectivity in Armies is his account of the evening at the Ambassador Theater. Whereas Time portrays Mailer "stumbling" about the auditorium, incoherently spewing a "scatological solo," the novel delves into Mailer's reactions to his audience, and the power struggles between the authors on the stage, which would have been invisible to anyone not participating in them. By placing his retrospective account in conversation with Time, a proxy for supposedly trustworthy news coverage, Mailer positions himself as the epistemological authority on this event. From the opening pages of the work, Mailer is playing with twin conceptions of "time," both in its manifestation as representative of traditional news media as a whole, and in its distorting effects of retrospection on storytelling. The novel is framed as an attempt to supersede both of these impediments to understanding, working to "leave Time in order to find out what happened." ${ }^{50}$ With his intimate knowledge of what occurred, and, more importantly, his very dispensing with a claim to objectivity, he invites readers to place their trust in the authority of his experience, placing (as Mailer writes) "adjectives" and especially "adverbs" (that is, qualifications of perception) beyond the authority of traditional reporting. ${ }^{51}$

Collaterally, he is then well-positioned to expound his own views. Unlike Thompson, for whom creation of image is not the stated aim, but a byproduct of his writing, Mailer presents himself as setting out with the explicit intention of recreating himself in the image-world in the first half of the work, so as to provide the reader with a metric against which they can measure his report in the second half. Through what he alerts readers to- "our intimacy with the master builder" of the narrative itself - the reader can account for whatever limits they perceive in Mailer's own ability to report accurately. ${ }^{52}$ During the early stages of the March, for example, Lowell and Mailer arrive to the sound of music, which the author initially notes "was being played by the Fugs," but which Mailer quickly qualifies (being "scrupulously phenomenological").

48 Mailer, The Armies of the Night: History as a Novel, the Novel as History, 53.

49 Ibid., 53.

50 Ibid., 4.

51 Ibid., 282.

52 Ibid., 218. 
As per usual, Mailer places himself in the third person: "Mailer heard the music first, then noticed the musicians and their costumes, then recognized [...] it was the Fugs." ${ }^{3}$ By comically highlighting the issue of phenomenology, Mailer demonstrates an awareness of the audience's concerns, and preempts their questions before they even have them.

Thompson and Mailer thus adopt somewhat divergent strategies. By grounding himself in the first-person, Thompson plays on the epistemological authority of experience to give weight to his account; he then crafts his argument through the symbolic representations that largely appear through hallucination. Mailer, on the other hand, constructs his argument through a multifaceted approach to documentation, which addresses the weaknesses of both subjective and objective reporting so as to craft the truest retelling possible. "The History as Novel" contains both the strengths and weaknesses of subjectivity, strong in its documentation of the "history of himself" - the story of an individual experience-and yet, it is weak in its necessarily limited scope. "The Novel as History" is in turn the embodiment of objectivity, with strength in its far-reaching account of events, and weakness in its necessarily biased universalization. As Begeibing comments in his Acts of Regeneration, Mailer responds to traditional objective journalism by "fusing the personal truths of the experience with the events themselves" and sits with the understanding that "neither kind of truth is exclusive to either book." 55 By operating in both modes, Mailer is able to account for the flaws of both the Novelist and the Historian, using the strengths of each to balance out the weaknesses of the Other.

The central event in Armies of the Night, the March on the Pentagon, exemplifies Mailer's skill at hewing metaphorical meaning from literal events. He considers the purpose of the March itself "to wound [the Pentagon] symbolically," extending the ideas that he had developed as far back as "The White Negro." ${ }^{56}$ In that essay, he suggested that hipsters, who (as he saw it) in Armies make up the shock troops of the March, seek to live not within the world, but outside of it, in a life and reality of their own creation. They interact with the world through energy and vibrations, where every interaction ends in either an increase or decrease in the energy that one possesses, and thus one's ability to perceive the world. Mailer sketches the mindset of the marchers in the same terms, as they seek not military victory, but instead "new kinds of victories [that] increase one's power for new kinds of perception." 57 Through this language of perception and energy, Mailer is able to construct a retelling of the event, which operates simultaneously on the literal and figurative level. He re-forms the march into symbolic civil war while simultaneously portraying the reality of what occurred.

53 Ibid., 119.

54 Ibid., 215.

55 Begeibing, Acts of Regeneration: Allegory and Archetype in the Works of Norman Mailer, 141.

56 Mailer, Norman. Advertisements for Myself. (Penguin Books, 2018), 54

57 Mailer, 76. 
Upon arrival at this climactic scene, the first detail that Mailer notes is the chaotic mix of cymbals, chanting, and spoken word played by the Fugs. Throughout the beginning of the Pentagon episode, much of Mailer's attention is focused on the Fugs' role in the Yuppie army's attempt to raise the Pentagon "three hundred feet," where it would then "turn orange and vibrate until all evil emissions had fled this levitation." 58 Through his description of their production, Mailer implicitly draws a parallel between the intention of the Fugs's artistic performance and his own:

The exorcism would proceed, and the Fugs were to serve as a theatrical medium... While the Indian triangle and the cymbal sounded, while a trumpet offered a mournful subterranean wail, full of sobs, and mahogany shadows of sorrow, and all sour groans from hell's dungeon, while finger bells tinkled and drums beat, so did [Ed Sanders, lead vocalist of the Fugs'] solemn voice speak something approximate to this. ${ }^{59}$

Mailer then goes on to describe Sanders' extended meditation on the evils of the war in Vietnam. Here, in their role as "theatrical medium" the Fugs act as both representative of, and conduit for, experience, as their music simultaneously reflects and feeds the energy of the crowd. Meanwhile, Mailer does the same, recording the event while he participates in it, chanting along with the crowd. He describes a paper passed around in the terms of mutual co-construction of experience: "By the act of reading this paper, you are engaged in the Holy Exorcism," a collective understanding of what the event is and yet also how a common vision means to transform it. ${ }^{60}$

At the same time, the phenomenological information that Mailer conveys is permeated by a tone that matches the strangely serious and absurd approach of the protest itself. While the Fugs chant about the Pentagon's first grope-in for peace, for instance, Mailer finds himself musing about how his "three divorces and four wives" have forced him to concede "the absolute existence of witches." ${ }^{11}$ Though the protest of the Pentagon is deeply serious - addressing, after all, the horrors of war in general and the Vietnam War in particular-neither Mailer nor his Yippie shock troops can seem to broach the subject without a bent towards the ridiculous, or even the irreverent. Thus, by jumping back and forth between documentary and experiential modes, from straining "to see what was going on at the head of the column," over to the Fugs playing "Out, demons, out!" to the people "streaming [...] to see what the attack had developed," Mailer mimics the head-turning hysteria of the March. ${ }^{62}$

Yet, as Mailer's participation in the event comes to its conclusion, his narration snaps back into the Novelist's sharp focus on minute detail and reader-absorption. After

58 Mailer, The Armies of the Night: History as a Novel, the Novel as History, 120.

59 Ibid., 120-121.

60 Ibid., 121.

61 Ibid., 122, 123.

62 Ibid., 126. 
stepping past the rope meant to separate the marchers from the Pentagon, what occurs next is illustrated in stark relief, and in a coherent, logical order:

The MP's stood in two widely spaced ranks. The first rank was ten yards behind the rope, and each MP in that row was close to twenty feet from the next man. The second rank, similarly spaced, was ten yards behind the first rank and perhaps thirty yards behind them a cluster appeared, every fifty yards or so, of two or three U. S. Marshals in white helmets and dark blue suits...He made a point of stepping neatly and decisively over the low rope. Then he headed across the grass to the nearest MP he saw. It was as if the air had changed, or the light had altered; he felt immediately much more alive-yes, bathed in air-and yet disembodied from himself, as if indeed he were watching himself in a film where this action was taking place. He could feel the eyes of the people behind the rope watching him, could feel the intensity of their existence as spectators. ${ }^{63}$

Mailer takes time to describe the smallest details, from his augmented perception of the light, to his feeling of being watched, to the "naked stricken lucidity" of the military police as he strides towards them. ${ }^{64} \mathrm{He}$ also returns to an extended meditation, making attempts at recreating the interiority of the MP in front of him, wondering whether he quivered from a "desire to strike [Mailer], or secret military wonder [...] now possessed of a moral force which implanted terror in the arms of young soldiers." 65 Throughout this sequence, he refers back to the air quality, calling it "mountain air," though Washington sits firmly near sea level. He ceases referring to it as such only when he is finally brought away from the crowd and is placed out of view. ${ }^{66}$ In doing so, Mailer sets apart those moments at which his image is being created - when he is on display — not only for the people present, but also for those who will watch the BBC footage later on. Mailer writes of having felt-in a variation on Thompson's claim, quoted earlier-at once "more alive [...] and yet disembodied from himself, as if indeed he were watching himself in a film where this action was taking place." ${ }^{67}$ Mailer paints himself as aware, in the moment of experience, of the simultaneity of the real and the image. He feels that his actions were being recorded, whether on video or in memory, shaping his conception in the public consciousness.

Though Eason's separation of ethnographic realism and cultural phenomenology offers a critically important approach to New Journalism, Thompson and Mailer both illustrate that the distinction is not as dichotomous as Eason might suggest. For Thompson, representation of reality is not consistently an active, co-constructive act in conjunction for the reader, as Eason's categorization of Thompson as cultural phenomenologist might suggest. Though Thompson often qualifies the faithfulness

63 Ibid., 129-130.

64 Ibid., 130.

65 Ibid.

66 Ibid., 130, 138.

67 Ibid., 129. (Emphasis mine) 
of his account in "Breakdown on Paradise Boulevard," he presents the report to the reader as patently representative of what occurred, taken "verbatim" for the sake of "journalistic purity." 68 This sort of ostensible straightforwardness strays toward the realm of ethnographic realism in that it assumes a shared perception with the reader, namely that verbatim recordings are a "purer" representation of reality than memory or perceptual experience. However, the section also has elements of cultural phenomenology: it cedes the fragmentary nature of reality (indeed, the manuscript is "splintered," acknowledging the inability to communicate that perceptual experience). These sorts of paradoxical, intermediate moments expose the weaknesses of Eason's categories. Though they are at times not as strictly separate as one might wish, they still prove useful in the framework that they provide to describe the reciprocal interaction of the image-world and reality in these pieces, and how Thompson and Mailer's understanding of that relationship shapes their reconstruction of self.

In spite of the fact that the world appears irreparably fractured, into brutish factions that populate Washington and Las Vegas, Mailer and Thompson both use the imageworld as a tool to construct a more stable, cohesive self. The March, for Mailer, is an almost incommunicably chaotic event; however, by placing himself at the center of it in his retelling, he builds an image of Norman Mailer which, though at times confusing and complex, is nonetheless solid. This reconstitution of the self comes as a result of the interplay of reality, in his actions, and the image-world, in his book and other representations. By this self-reflexive recreation, he puts forth an addendum to Eason's categories, whereby the journalist is able both to penetrate the image to reveal the reality (for example in his rebuttal of the Time depiction) and to understand the implication and mutualistic relationship of the image on reality, and vice versa. Through these complications, we see how each journalist simultaneously supports and undermines Eason's distinctions. By bringing each category into question, and the two into conversation with one another, we can then most fully explore these modes of representation.

68 Thompson, Fear and Loathing in Las Vegas: A Savage Journey into the Heart of the American Dream, 161. 


\section{BIBLIOGRAPHY}

Begiebing, Robert J. Acts of Regeneration: Allegory and Archetype in the Works of Norman Mailer. Columbia: University of Missouri Press, 1980.

Eason, David L. "The New Journalism and the Image-World: Two Modes of Organizing Experience." In Critical Studies in Mass Communication, 1984.

Hollowell, John. Fact \& Fiction: The New Journalism and the Nonfiction Novel. Chapel Hill: University of North Carolina Press, 1977.

Mailer, Norman. The Armies of the Night: History as a Novel, the Novel as History. Plume, 2017.

Mailer, Norman. Advertisements for Myself. London: Penguin Books, 2018.

Thompson, Hunter S. Fear and Loathing in Las Vegas: A Savage Journey into the Heart of the American Dream. New York: Random House, 1998.

Thompson, Hunter S. The Great Shark Hunt: Strange Tales from a Strange Time. London: Picador, 2012.

Zavarzadeh, Mas'ud. The Mythopoeic Reality: the Postwar American Nonfiction Novel. Champaign: University of Illinois Press, 1976. 